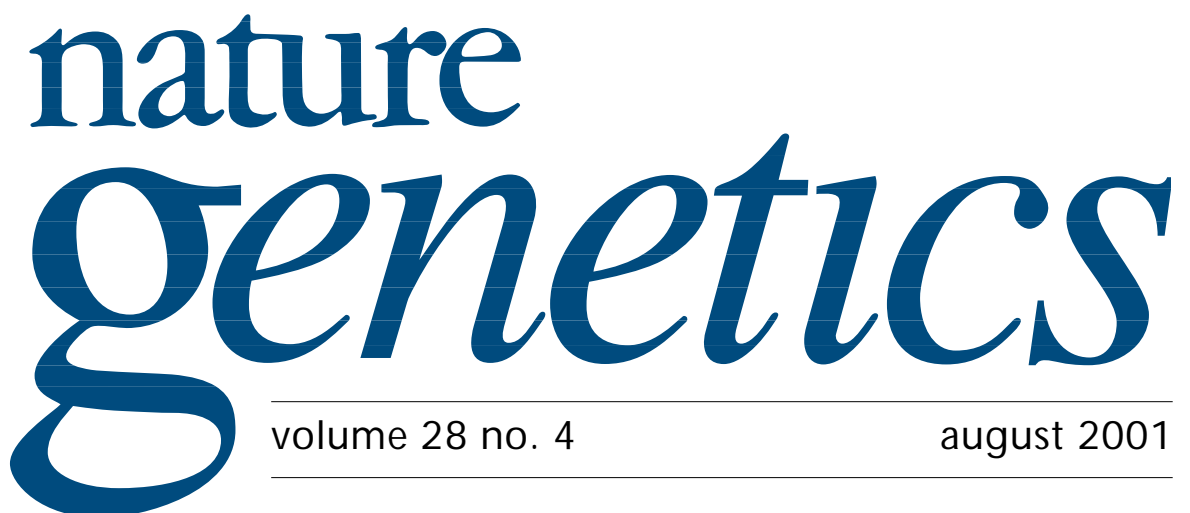

\title{
Defining a new bioethic
}

With so much attention now being given (deservedly) to the development and containment of genomics within an ethical framework, the whole question of ethics and what it means for genomics warrants close examination. The Oxford English Dictionary defines ethics as "the science of morals in human conduct". Implicit in this definition is a challenge that the genomics community is only beginning to tackle. Do we want to develop bioethics as an abstract pursuit, describing and exploring the moral constructions that society is building around genomics, or do we want to provide pragmatic, moral guidance to all that are affected by genomics? To put it more bluntly, do we want 'ethics as usual' or should we in fact be defining a new bioethics that promises real world solutions to real world problems?

In the context of genomics, 'ethics as usual' might reasonably be thought of as the domain of academic moralists - the application of philosophical (or legal) theory to a clinical or research question. For many, 'ethics as usual' is overly simplistic and sanitized, providing solutions that do not reflect the nuances of real-life situations. It deals with single-discipline issues and lacks any real collaboration between legitimate stakeholders. As such, some see it as dismissive of or demonizing industry and only rarely contributing to a broader collaborative effort to help the research community, industry and others understand how their work may impact society and indeed how to involve society in discussions (and decisions) about genomics and its impact globally. The work of traditional ethicists is most likely to be published in ethics journals (where ethicists talk to ethicists).

Some worry that the major bioethics establishments such as the US National Human Genome Research Institute's ELSI (Ethical, Legal and Social Implications) program spend too much time drawing up lists of rules and restrictions on how genomics technologies should be applied in particular circumstances. Whereas there is a place for rules and regulations (don't clone people; don't discriminate; don't steal personal information, and so on) this narrowly defined focus on specific questions of relevance to only a few players should not be the dominant activity of ELSI programs. Indeed the NHGRI ELSI program (and their US Department of Energy colleagues), recognize some of these weaknesses. An objective and thoughtful February 2000 internal report (www.nhgri.nih.gov/ELSI/erpg_report.html) criticized the overall program as "skewing . . . the entire ELSI portfolio toward research projects that address specific and somewhat narrowly focused questions and away from projects that focus more broadly on the interactions between genetic issues and other aspects of the health care environment or society at large... a need still exists for greater cross-fertilization among ELSI researchers and for more 
involvement in ELSI projects by professionals in disciplines that have traditionally been underrepresented in ELSI research."

It is not surprising therefore that critics offer the above description as a caricature of traditional ethics; it is also the basis for a call for change in how we practice bioethics in contemplating an increasingly potent, challenging and exciting genomics future. Putting aside the distortions associated with such a general (and perhaps somewhat exaggerated) characterization of 'ethics as usual', and considering the myriad ethical challenges of modern genomics, is it the best we can do? What are the characteristics of a new bioethics as it applies to genomics?

Peter Singer and Abdullah Daar of the University of Toronto Joint Centre for Bioethics are tackling just these questions as they and their colleagues build the "Canadian Program on Genomics and Global Health", part of the C $\$ 300$ million Genome Canada initiative and the "Program on Applied Ethics and Biotechnology". Singer and Daar see the new bioethics as being a pragmatic approach to maximizing the benefits and minimizing the risks of genomics. An essential component of this effort is the transdisciplinary collaboration between all stakeholders including academia, industry, government, NGOs and others. Although it is certainly popular these days to talk about transdisciplinary programs that are inclusive and open to all parties, such a broad-based involvement goes to the heart of the new bioethics. It forces ethicists (traditional and otherwise) continually to check that their assessments and proposed solutions are relevant and appropriate to parties who use genomics in the research and commercial market place.

Another essential characteristic of this new bioethics is a global (or at least international) perspective. If we accept that genomics will probably have an impact on all people, we must also recognize that the principles and morals that govern its application must take into account the needs and circumstances of all people. Indeed much of the new bioethics rationale stems not from an academic understanding of the moral construction surrounding genomics but instead from a recognition that it is not ethical to allow genomics and other disciplines of tremendous potential to develop in a way that does not optimize the benefits to be gained, particularly for those who are already disadvantaged.

And in this respect, the new bioethics of genomics becomes indistinct from the ethics that should govern other areas of research and their application. Harvard economist Jeffrey Sachs argues for macro economic policies that will help lift the poorest out of the poverty trap (www.cid.harvard.edu/ciddirector) and The International Council for Global Health Progress (www.cipgs.org) seeks “...to extend to everyone everywhere the benefits of modern medicine". Although neither classify their agendas as overtly ethics-based pursuits, each practices the new ethics of cooperation and globalization. So too must the genomics community, interpreting and framing their day-to-day activities in the light of this emerging sensitivity, mindful of the challenge to think broadly about how genomics should be maximally mined with the needs of as many people as possible taken into account.

None of this is to say that 'ethics as usual' is an unworthy pursuit or that those that practice it are doing us a disservice. On the contrary, scholars of theory and philosophy at the heart of traditional ethics have helped us to understand the motivations behind actions that we intuitively feel to be right and moral; through their work we come to better understand the distinction between rights and duties. But all too often this approach does not yield an understanding or direction that enables us to make pragmatic decisions concerning the future development and emphasis of genomics and other technologies. It is for this reason that we need to define a new ethic of genomics; a pragmatic bioethics that leans closer to utilitarianism, encouraging dialogue amongst different sectors and addressing the needs of an increasingly unequal and demanding global society.

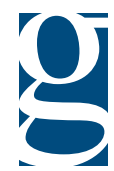

